\title{
Multiculturalism In Higher Education (HE); Fact Or Fiction?
}

\author{
Dr Sue Jones, David Timmins, Dr David Wood, \\ Dr Po Li Tan and Dr Sian Howells \\ King's College London
}

Working in a Russell Group university can be a challenge in many ways and there can often be a preconception about students studying on our programmes. In the Department of Pharmacy, the ethnic mix of our undergraduates shows that they are mainly Asian $(>50 \%)$ and female $(>70 \%)$ with our ethnic 'minorities' comprising of white and black males. Interestingly, this mirrors the workforce data which shows that in 2009 registered pharmacists $68.5 \%$ were 'white' and $65 \%$ of pharmacists aged over 40 years old were female (Seston and Hassell, 2010).

When the term 'multiculturalism' is used, one needs to define and understand what this means. Hofstede (1991) defined culture as, "the collective programming of the mind which distinguishes the members of one group or category of people from another", (Hofstede,1991, 5).

His definition really bears no reference to the superficiality of suggested meaning often implicit of other's ideas around 'culture'; race, religion or ethnicity (Breakwell, 1986; Hall and du Gay, 1996). We would reject most definitions of culture in so far as they try to describe or define the term so narrowly that the definition itself divides people. Roger's (2003) client-centred approach would more closely match our definition so that culture can 'be', in Heideggerian (2005) terms, anything you want it to 'be'. So that whatever individuals or groups bring to an interaction, should be respected and recognised; whether that is the culture of age, gender, ethnicity, sexuality, dependence, illness or ability, is irrelevant. Working together to understand perspectives and some of the perceived barriers develops cultural awareness. So perhaps, by application of our 'cultural' understanding maybe multiculturalism is in the positive application of 'culture'. That it is the ability to relate to groups and categories of people by recognising and embracing difference rather than recognising, ignoring and discouraging obvious differences.

Taking this as a reasonable working hypothesis then suddenly we are at a transition. Our current research hypothesises that our students, both undergraduates and healthcare professionals (HCP), have a lack of understanding of the broader concepts of culture. So, we have developed and evaluated a pedagogical strategy to engage these groups to discuss culture. This involved teaching in the form of lectures, a psychometric test, workshops and developing reflective writing skills in pharmacy undergraduate students and $\mathrm{HCP}(\mathrm{N}=346 ; \mathrm{N}=9$ respectively). From this, we have found that some of our findings are at odds with our hypothesis: "there are no differences really...we are all brown and Indian." (S1C3)

This student exemplifies an innocence that Bennett (1986) would term 'reversal'. Although born in Kenya, this student has rejected their own heritage in favour of another ethnicity. Surely then, the student has a lack of multiculturalism. A further example: "I am a Hindu living in London....therefore I am multicultural." (S5C1) 
This student demonstrates a common misconception that having many cultures around you makes you, by default, multicultural.

We would propose that the naivety shown by our students is simply due to an immaturity and a general lack of 'exposure' to the variety of difference around them. Perhaps May and Kruger's (1988) management metaphor of 'unconsciously incompetent' could be melded with Bennett's (1986) continuum to assist in explaining the lack of, or confined world-view of our students.
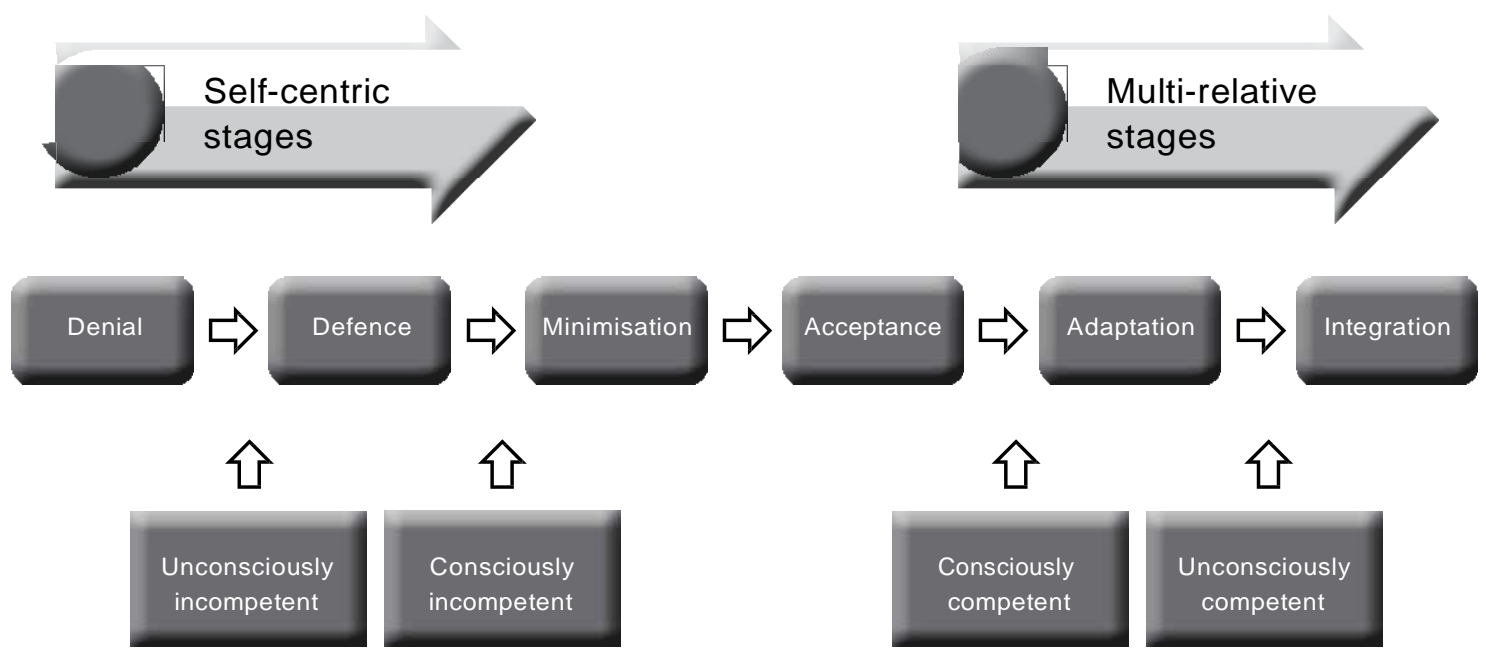

Figure 1 Developmental stages in cultural awareness (after Bennett (1986) and May and Kruger (1988))

Whilst others talk of culture and multicultural, our group thinks that some of these terms are redundant and divisive and rather than embracing, actually marginalise those they seek to assist. As seen from our research, students are culturally naive and they have a very narrow view of the world outside of their own cultural contexts. They enter into higher education with a lack of perception and understanding of the contexts in play in a multicultural society and the huge number of different influences. This can often lead to them further dividing themselves and not mixing with students different to themselves as illustrated by another student: "before I just had Asian friends that I hung around with, but (through cultural awareness and sensitivity teaching) now I have completely changed,...(my friends are)...Irish...Polish....and Chinese." (C3FG3)

We would like to propose the term 'cultural awareness and sensitivity (CAS)' may be more appropriate to encapsulate the considerations of interactions between people. CAS is the ability for an individual to interact with another individual or group of individuals showing empathy, awareness, sensitivity and regard for all aspects of their persona(s). In particular, with a deep respect and consideration for the individual's background, the relative nature of how these factors interplay and the relative importance of them to that individual. By working together and sharing cultural similarities and difference without the fear of being labelled prejudice then perhaps multiculturalism, as a utopian value, in higer education can be pursued. 


\section{References}

Bennett, M. (1986) A Developmental Approach to Training for Intercultural Sensitivity. International Journal of Intercultural Relations, 10, pp. 179-196.

Breakwell, G. (1986) Coping with Threatened Identities. London: Methuen and Co Ltd.

Hall, S., and du Gay, P. (1996) Questions of Cultural Identity. London: Sage.

Heidegger, M. (2005) Being and Time. Oxford: Blackwell. (First translated in 1962).

Hofstede, G. (1991) Cultures and Organisations; Intercultural Co-operation and its Importance for Survival. London: Profile Books.

Leask, B. (2006) Plagiarism, Cultural Diversity and Metaphor - Implications for Academic Staff Development. Assessment and Evaluation in Higher Education, 31 (2), pp.183-199.

May, G. D., and Kruger, M. (1988) The Manager Within. Personnel Journal, pp. 57-65.

Rogers, C. (2003) Client Centered Therapy. London: Constable and Robinson Ltd. (First published in 1951).

Seston, E., and Hassell, K. (2010) Workforce Update - Joiners, Leavers and Practising and Non-practising Pharmacists on the 2009 Register. Pharmaceutical Journal, 284, pp. 80-82. 